\title{
Modeling of Complex Life Cycle Prediction Based on Cell Division
}

\author{
Fucheng Zhang, Yahui Wang, and De Zhang \\ Institute of Electrical and Information Engineering, Beijing University of Civil Engineering and Architecture, Beijing 100044, China \\ Correspondence should be addressed to Fucheng Zhang; 475521864@qq.com
}

Received 9 August 2017; Accepted 16 October 2017; Published 3 December 2017

Academic Editor: Chunhui Zhao

Copyright (C) 2017 Fucheng Zhang et al. This is an open access article distributed under the Creative Commons Attribution License, which permits unrestricted use, distribution, and reproduction in any medium, provided the original work is properly cited.

Effective fault diagnosis and reasonable life expectancy are of great significance and practical engineering value for the safety, reliability, and maintenance cost of equipment and working environment. At present, the life prediction methods of the equipment are equipment life prediction based on condition monitoring, combined forecasting model, and driven data. Most of them need to be based on a large amount of data to achieve the problem. For this issue, we propose learning from the mechanism of cell division in the organism. We have established a moderate complexity of life prediction model across studying the complex multifactor correlation life model. In this paper, we model the life prediction of cell division. Experiments show that our model can effectively simulate the state of cell division. Through the model of reference, we will use it for the equipment of the complex life prediction.

\section{Introduction}

Industrial systems and large-scale application equipment work in the long term in the high pressure fluctuations, corrosive, and other harsh environments. After a certain period of time, it will inevitably fail. When the fault is repairable, maintenance is usually done, but the maintenance of the defective parts will generally reduce the accuracy, performance, and reliability of the equipment. It ultimately leads to degradation of equipment functions and improves the overall cost of equipment spending. With the increase in the number of equipment repairs, the degree of functional degradation and maintenance costs gradually increased [1]. Therefore, when we make decisions on repairing industrial systems and large equipment, we need to balance the factors like prolonged service life, equipment downturn, increased cost, and other factors. After several repairs, the functional decline in the equipment and the total cost of the expenditure are greater than the extension of the life of the industrial equipment. At this point, it makes no sense to continue to repair. In order to avoid overrepair, we need to do a proper repair of the equipment and estimate a reasonable life, Ensuring the balance between safety and economy of industrial equipment and realizing the health management of gas industrial equipment in complex environment. It is necessary to establish a life forecast of industrial equipment related to multiparameters (including operating environment, service life, functional recession, and cost stacking) model. In order to establish an effective model for predicting equipment life, we learn from the biological perspective and abstract the life prediction model of the normal equipment from the biological life model.

Determining the life of industrial equipment involves many factors, and its use environment is very complex. In principle, it can be compared to the determination of biological life as shown in Table 1. In order to predict the life of industrial equipment, we need to draw on the life prediction method of the cell to obtain the mathematical model of the limited life of industrial equipment [2].

Figure 1 is a schematic diagram of the industrial equipment life estimation based on the limited division mechanism [3] of biological cells. Its main body has two parts: one is the industrial equipment system and the other is the biological system. We divided the factors that affect the life of the living body to internal factors and external factors. The same factors affecting the life of industrial equipment are also divided into internal factors and external factors. The establishment of a life-based estimation model based on the limited division mechanism of biological cells requires a clear understanding of the process structure of cell division (the 
TABLE 1: Analogy of fault diagnosis in biology and engineering.

\begin{tabular}{ll}
\hline Medical science & Engineering \\
\hline Disease diagnosis & Fault diagnosis \\
Through observation, laboratory tests, and medical equipment & Through sensors, signal processing and testing instrument \\
The conclusion is given by the doctor & The conclusion is given by diagnostic software \\
$\begin{array}{l}\text { Multidisciplinary consultation } \\
\text { The doctor diagnosed the disease in many ways }\end{array}$ & Comprehensive diagnosis \\
$\begin{array}{l}\text { Disease prevention and health care } \\
\text { Physical examination, disease prediction, health care system }\end{array}$ & Diagnose current faults with multiple diagnostic techniques \\
(health, subhealth, life expectancy, and safeguard measures: past, & Fault diagnosis and health management \\
present, and future) & subhealth, failure, component life prediction, decision/maintenance \\
\hline
\end{tabular}

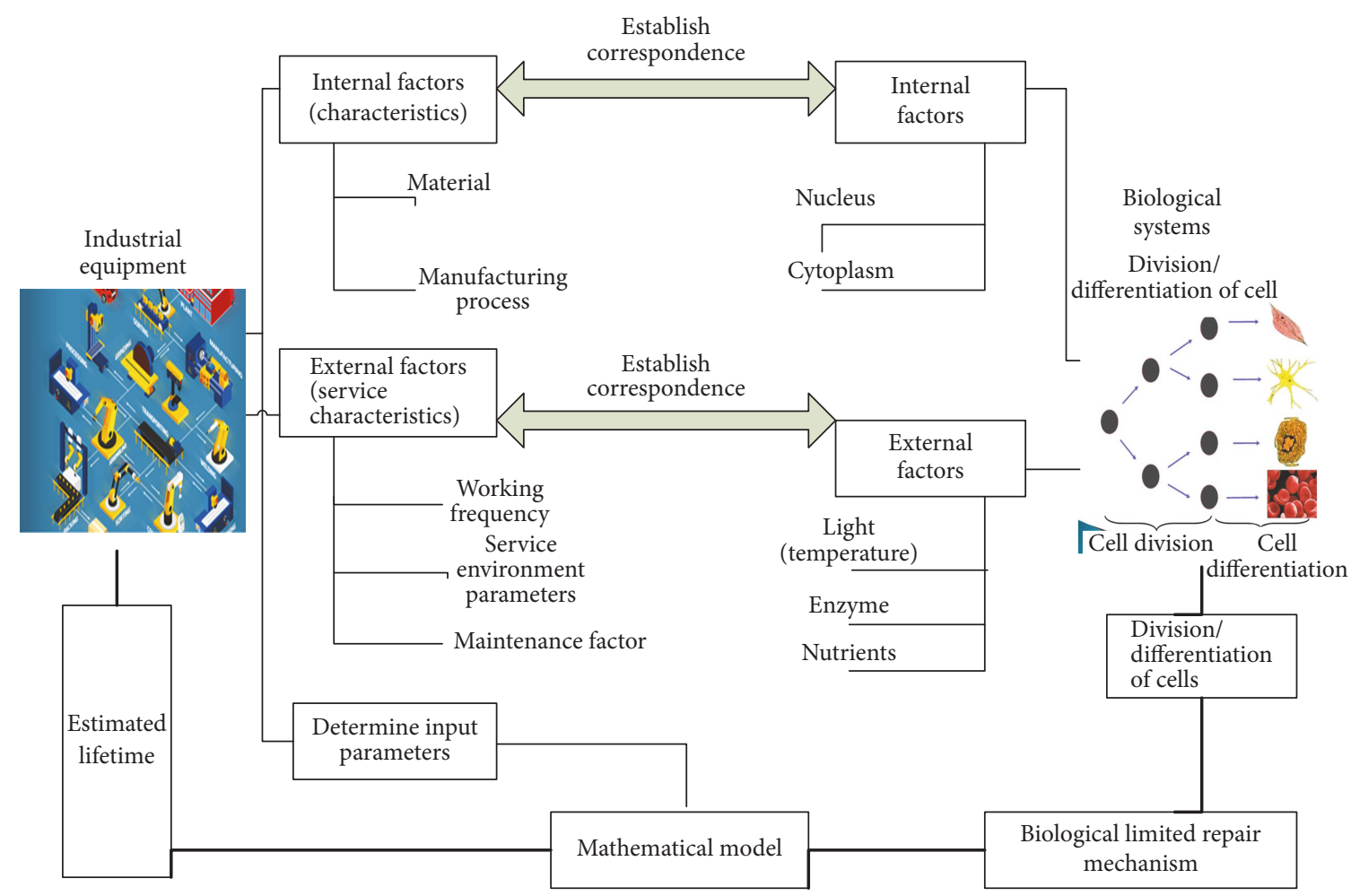

FIGURE 1: A schematic diagram of biological cell finite splitting mechanism and industrial equipment life estimation.

limited repair mechanism of the organism). Second, it is necessary to clarify which parameter variables are related (internal nuclear parameters, external light, nutrients, and other factors). A mathematical model for estimating the life expectancy of industrial equipment with moderate heterozygosity is abstracted from the limited repair mechanism of organisms. The relation between the parameter variables of an organism and the physical parameters of an industrial device determines the input of the mathematical model for the estimation of the lifetime of an industrial device and ultimately to achieve the purpose of estimating the life of industrial equipment and to achieve a reasonable, nonexcessive maintenance.

\section{Complex System}

The study of complex systems was the rise of the "Complex Systems," the album published by the University of Science on April 2, 1999. Its emergence is closely related to the study of complexity. The question about complexity originated in Austria, and in 1928 Bertalanffy raised the question of complexity for the first time in his essay on "biological organism systems."

A system is a combination of elements that interact more and more with each other. Any system has three aspects that need to be studied: entity, attribute, and activity. Because of the interaction between the entities that make up the system, the concept of "state" is usually described. The research system is to study the state change of the system, that is, the evolution of the system.

\subsection{The Classification and Characteristics of the System}

(1) According to the Size of the System. There are small system, large system, and giant system. 
(2) According to the Degree of Association for Subsystems within the System. There are simple system and complex system.

(3) According to the System and the outside World Contact Situation. There are isolated system and open system.

The term "complex system" appeared on the "Complex Systems" published by the University of Science on April 2, 1999, and the magazine made a brief description of the "complex system": by understanding the components of a system (subsystems), the nature of the system cannot be fully explained, and such systems are called complex systems. The complex system is characterized by high order, being multiloop, being nonlinear, multitime scale, being hierarchical, openness, uncertainty, morbid structure, and so on [4].

\section{Cell Division Systems in Organism}

Medical experiments have amply demonstrated that the human body's fiber cells can only be divided into 50 to 60 generations; thus the human lifespan is limited [5]. The discovery of cell-limited division mechanism has opened a wide world for the discussion of "biological life" from the cell level. Postdoctoral Blackburn at Yale University found telomere structure of the end of the cell chromosome; further studies have also found telomerase; the role of telomerase is to take off the telomere to replenish up, so that, for telomere to maintain a certain length, the cell can continue to divide and to avoid aging and apoptosis. However, after the differentiation and maturation of various tissues in normal adults, the gene for producing telomerase was closed. It can be seen that in the process of human evolution, the mechanism of cell cycle regulation has evolved into a very ingenious system, which controls cell division properly and ensures the stability, rapidity, and accuracy of cell division.

The parameters that affect cell division are as follows: (1) Cell volume: DNA, RNA, ribose, and proteins make up the quality of the cell; the cells must meet some of the necessary conditions before splitting, one of which is the duplication of DNA; (2) the interaction force between the nuclei: during the period of normal metabolism, there is interaction between the nucleus and the cytoplasm (with the exchange of matter, energy, and information, internal and external factors); (3) regional area mass density having an effect on cell division; (4) the rate of cell division related to various environmental factors.

Cell division is the basis of cell differentiation, tissue renewal, and biological reproduction. As early as 19th century, the researchers analyzed the process of cell division, which was based on qualitative analysis, and quantitative analysis can help to study the biological reaction process of various factors within the cell division and analyze the details of cell division.

Figure 2 shows each stage of cell division.

Cell cycle refers to the normal continuous division of cells from the previous mitosis to the next time of the completion of the continuous dynamic process, but also multistage, multifactor participation in the precise and orderly regulation process, which can be divided into 5 periods, that is, G0

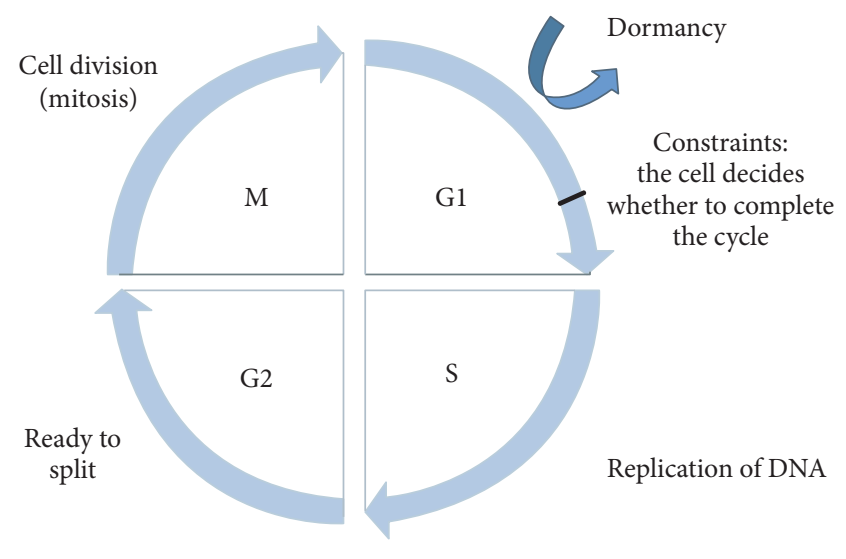

FIgure 2: Cell division cycle.

period (Gap0, resting period), G1 period (Gapl, prophase of DNA synthesis), S phase (DNA synthesis phase, DNA synthesis period), G2 period (anaphase of DNA synthesis), and $\mathrm{M}$ phase (mitosis, mitotic period). Two main limit points are found, that is, $1 \mathrm{G} / \mathrm{S}$ limit points (from G1 phase to $S$ phase control cells can prevent the damage of base replication and repair mutation of chromosome) and G2/M limit point (cells in two control points can make the cell before the split phase repairing on the duplicated DNA damage). By limiting the point, even if the stimulus signal is removed, the cell will still begin to replicate DNA. There are many enzymes involved in the mammalian cell cycle. But one of the most important enzymes is a group of two complexes, which act as a cyclic protein-dependent kinase (CDKs) and a group of periodic proteins (cyclins), which act as a subunit of the subunits and are a kind of very significant silk/threonine protease $[6,7]$.

The main research content of this paper is to systematically analyze the cycle of cell division from the point of view of the system and analyze the influence of the elements in the cell on the cell division cycle from the simulation. The relationship between cell life cycle and internal components of cells was obtained. The relationship between cell cycle and internal components was obtained by simplifying the cell cycle by cell distribution.

\section{Analysis and Modeling of Cell Division Systems}

\subsection{The Role of Various Cell Division Proteins and Their Influencing Factors}

Gene Regulatory Protein E2F, pRB. Most animal cells over the initial checkpoint rely on regulatory protein-inducible G1/S gene expression. The most important ones of these regulatory factors is the E2F family, which regulates the expression of most genes in the G1 term (e, a). The precise regulation of the E2F activity ensures that the G1/S gene is expressed at the appropriate point in the cell cycle. However, the function of E2F is mainly controlled by PRB protein, and in stationary cells, $\mathrm{pRB}$ inhibited the expression of E2F target gene. 
$p R B p$ Protein. It provides a cell cycle brake device, but it is not essential to regulating the cell cycle process but mainly involved in cell cycle withdrawal and maintenance of cell resting state. When E2F-dependent protein expression is not inhibited by $\mathrm{pRB}$, the cells exit the mitosis directly from the Start checkpoint.

CDK Inhibitory Protein. P27 is a protein that has negative effects on CDK kinase activity in cells. It can inhibit the binding of $\mathrm{CDK}$ kinase and play an important role in the negative regulation of cell cycle.

Cycle Protein D. Cyclin D mainly regulates the G1 phase of cells, and its major synthesis is activated by AP1 (activation of growth factor GF). The transcription factor E2F promotes it, the inhibitory factors $\mathrm{pRB}$ and $\mathrm{pRBp}$ inhibit its transcription, and cyclin $\mathrm{D}$ can activates the cycle protein-dependent enzyme Cdk4-6, and then the active complex in the cell cycle plays the primary role of $\mathrm{pRB}$ phosphorylation into $\mathrm{pRBp}$.

Cyclic Protein E. Cyclic protein E mainly regulates G1/S phase, and its synthesis is mainly activated by E2F, and it is inhibited by $\mathrm{pRB}$, which can be rapidly degraded by skp2. Cycle E can activate $\mathrm{Cdk} 2$ protein $\mathrm{E}$. The main role of the synthetic complex cyclin E/Cdk2 is to phosphorylate $\mathrm{pRBp}$ to $\mathrm{pRBpp}$, followed by phosphorylation of p27 to degrade, and when p27 is degraded, the cells cross the G1/S test point and enter the S period.

Cyclic Protein A. Cyclic protein A mainly regulates the cell $S$ phase and crosses S/G2 checkpoint. Its synthesis is mainly affected by E2F activation, while being inhibited by $\mathrm{pRBp}$ with degradation of APC-PCdc20. Cyclin A activates Cdc2 to form a complex, cyclin A/Cdk2, which is inhibited by p27 binding in the G1 phase and then released in the S phase. The complex can phosphorylate E2F simultaneously, reducing the synthesis of cyclin D, cyclin E, and cyclin A and inactivating APC (late-promoting complex). APC (late-promoting complex) is a large E3-linked enzyme that mediates cell cycleregulated proteins that rely on ubiquitin-hydrolyzed proteins to control events during replication and cell division, combining ubiquitin and substrate, and degrade by proteasome.

Cycle Protein B. Cycle protein B mainly controls cell internal checkpoints across the G2/M and $M$. It is mainly suppressed by pRBp. It can be degraded by $\mathrm{APC}^{\mathrm{Cdh} 1}$. When $\mathrm{Cdk} 1$ is activated, complex cyclin $\mathrm{B} / \mathrm{Cdcl}$ nuclear protein phosphorylation fiber layer will trigger the nuclear membrane decomposition while phosphorylating APC, so that APC can be activated by $\mathrm{Cdc} 20$. APC ${ }^{\mathrm{Cdc} 20}$ has a biodegradable effect on cyclin A and cyclin B. It breaks the protein safety factor, releases the isolated enzyme, destroys the connection between the sister chromosomes, and promotes cell mitosis.

\subsection{Internal Processes and Modeling of Cell Division Cycles}

4.2.1. Cell Division Process. Growth factor, GF, promotes the expression of cyclin D and cyclin D with cdk4-6 (cyclindependent kinases) and phosphorylates $p R B$ to $p R B p$, and with the decrease of PRB, E2F and cyclin E begin synthesizing. E2F synthesis accelerates the synthesis of cyclin $\mathrm{E}$ and cyclin A. Cyclic protein E can phosphorylate $\mathrm{pRBp}$ to $\mathrm{pRBpp}$, while promoting the inhibition of phosphorylation of protein p27 and then release periodic protein A. With the decrease of p27, cyclin A increases and the cells enter S phase. Cyclin A promotes the phosphorylation of E2F and degrades Cdh1. At the same time, the binding of APC to Cdhl is delayed and the APC is inactivated. A decrease in APC activity degrades cyclin E. During the release of cyclin B, the cell division cycle enters $M$ phase. At the same time cyclin B phosphorylated APC, during degradation of protein safety factor, and then released the separation of enzymes, to promote cell division.

4.2.2. Cell Division System Modeling. Cell division modeling consists of 3 parts [8]: synthesis, degradation, and regulation. The differential equation for each protein is

$$
\begin{aligned}
\frac{d \text { Cyclin }}{d t}= & V_{\text {synthesis }}-V_{\text {Degradation }} \\
& +\left(V_{\text {Activation }}-V_{\text {inactivation }}\right) .
\end{aligned}
$$

Synthesis Regulation. If $n$ transcription factor $\left(X_{i}\right)$ activates or suppresses the transcription of a gene and each gene is only combined with one transcription factors, the rate of periodic protein synthesis is

$$
\begin{aligned}
V_{\text {synthesis }}= & \frac{K_{0}+K_{1} * K_{M 1} X_{1}+\cdots+K_{n} * K_{M n} * X_{n}}{1+K_{M 1} * X_{1}+\cdots+K_{M n} * X_{n}} \\
& * \mathrm{DT},
\end{aligned}
$$

where DT is the gene concentration, $K_{M i}$ is the ratio of the transcription factor to the gene binding and separation, and $K_{i}$ is the transcription rate after the transcription factor binds to the gene.

Degradation Regulation. The degradation of protein $\mathrm{A}$ is regulated by the degradation factor $B_{i}$ in $n$ and each protein binds only to one transcription factor; then the degradation rate is

$$
\begin{aligned}
V_{\text {Degradation }}= & K_{0} * a+K_{1} * B T_{1} * \frac{n}{A+K_{M 1}}+\cdots \\
& +K_{n} * B T_{n} * \frac{A}{A+K_{M n}},
\end{aligned}
$$

where $B T_{i}$ is the total concentration of degradation factor $B_{i}$, $K_{M i}$ is the ratio of degradation factor and protein separation to synthesis, and $K_{i}$ is the degradation rate of degradation factor and protein synthesis.

Modification Regulation. Protein modification is an enzymatic reaction, which is mainly Rice kinetic:

$$
V_{\text {Activation/inactivation }}=K *\left[E_{0}\right] * \frac{[S]}{K_{M+[S]}} \text {. }
$$

$E_{0}$ is the total concentration of enzymes, $S$ is the substrate concentration, and $K_{M}$ is the Michaelis constant.

The process of synthesis modification of cyclin A in cells is as follows: 


$$
\begin{aligned}
\frac{d A}{d t}= & V_{\text {synthesis }} \\
& -\left(K_{0} * A+K_{1} * \operatorname{Cdc} 20 \mathrm{a} * \frac{A}{K_{M 1}+A}\right) .
\end{aligned}
$$

$d A / d t=0$; you can know when Cdc20a (it is cell cycle regulator $)=0$ that we get the maximum $A=V_{\text {synthesis }} / K_{0}$. When Cdc20a is large enough, $A_{\text {min }}=V_{\text {synthesis }} /\left(K_{1} *\right.$ Cdc20a $\left.-V_{\text {synthesis }}\right) * K_{M 1}$, in direct proportion to $K_{M 1}$.

Then the formula can be simplified as follows:

$$
\frac{d A}{d t}=-K_{0} * \frac{A^{2}-\left(V_{\text {synthesis }}-K_{1} * \operatorname{Cdc} 20 \mathrm{a}-K_{0} * K_{M 1}\right) / K_{0} * A-\left(K_{M 1} * V_{\text {synthesis }}\right) / K_{0}}{K_{M 1}+A} .
$$

Make

$$
\begin{gathered}
A^{2}-\frac{V_{\text {synthesis }}-K_{1} * \text { Cdc20a }-K_{0} * K_{M 1}}{K_{0}} * A \\
-\frac{K_{M 1} * V_{\text {synthesis }}}{K_{0}}=0 .
\end{gathered}
$$

Because of $\left(K_{M 1} * V_{\text {synthesis }}\right) / K_{0}>0$, the equation has two positive and negative solutions, which are assumed to be $A_{1}$ $(<0)$ and $A_{2}(>0)$. Then

$$
\begin{aligned}
& A_{1}+A_{2}=\frac{V_{\text {synthesis }}-K_{1} * \text { Cdc20a }-K_{0} * K_{M 1}}{K_{0}} \\
& A_{1} * A_{2}=\frac{K_{M 1} * V_{\text {synthesis }}}{K_{0}} .
\end{aligned}
$$

Therefore, formula (8) can be reduced to

$$
\frac{d A}{d t}=-K_{0} * \frac{\left(A-A_{1}\right) *\left(A-A_{2}\right)}{K_{M 1}+A} .
$$

Suppose $K_{M 1}+A=a *\left(A-A_{1}\right)+b *\left(A-A_{2}\right)$; then $A=A_{2}, d A / d t=0, A \neq A_{2}$; at that time,

$$
\frac{d A}{d t}=-K_{0} * \frac{1}{a /\left(A-A_{2}\right)+b /\left(A-A_{1}\right)} .
$$

In the time domain solution,

$$
\left(A-A_{1}\right)^{b}+\left|A-A_{2}\right|^{a *\left|A-A_{2}\right| /\left(A-A_{1}\right)}=R * e^{-K_{0} * t}
$$

when $t=0, A=0, R=\left(-A_{1}\right)^{b}+A_{2}^{-a}$, when $A>A_{2}$, $d A / d t<0$, and when $A<A_{2}, d A / d t>0$. When $t \rightarrow+\infty$, the steady-state value is $A_{2}$. Time constant $T=1 /\left(\left(\left(K_{1} *\right.\right.\right.$ Cdc20a $\left.\left.) / K_{M 1}\right)+K_{0}\right)$ mainly affected by $\left(K_{1} *\right.$ Cdc $\left.20 a\right) / K_{M 1}$. If we want to change the system's response rate, we can increase the value $\left(K_{1} *\right.$ Cdc20a) $/ K_{M 1}$.

The proteins involved in all expected processes during cell division are bound to follow this synthesis modification process.

\section{Simplification of Cell Division Model}

Cell division was mainly manifested in the form of intracellular protein cycle changing. Because cell division is a continuous process, the content of the protein that assists in completing the cell division is fluctuating. The main factor in maintaining this ongoing process was determined by the number of telomeres in the cell. When the number of telomeres was sufficient, the cells will divide when they receive excitation information. Until the number of telomeres was not sufficient to allow the cells to split, the division stopped.

But because of the limited telomere length, the process of cell division would cease when the telomere number drops to a certain extent. So we assumed that the number of intracellular telomeres was a linear descent process, assuming that the initial telomere number was $K$, each time in the division, the cells automatically shed $j$ telomeres; when the remaining amount of telomeres reaches the set threshold the cell division ends.

In the experiment, we assumed that, in the case of cells that had been activated, it was found that there was an internal cycle between cyclin A and cyclin B from a small cycle of division within the cell. We showed it in Figure 3. Assuming that the influencing factor in this cycle was sufficient, the split within a small cycle can continue. After neglecting some of the variables, we studied the periodicity of cell division, and we could show that the cell cycle was also expressed in this small cycle.

In the model without periodic protein $\mathrm{D}$, the factor $\mathrm{pRB}$ was assumed to be zero. After the absence of the pRB factor, its effect factor E2F has been at a high level without inhibition, so we assumed that E2F had been in high expression in the cell (at a fixed concentration). So we ignored the synthetic equation of E2F and its compounds. In the whole model, there was a cell growth factor, and because the growth factor only affects the stability of the first stage of cyclin D, we neglected cyclin $\mathrm{D}$, since the target of cyclin $\mathrm{D}$ was $\mathrm{pRB}$. Because of the absence of $\mathrm{pRB}$, the action product of cyclin $\mathrm{E}$ was absent, so the first function of cyclin $\mathrm{E}$ was ineffective. The function of cyclin E was phosphorylated by $\mathrm{pRBp}$, which promoted cyclin A (inhibited by $\mathrm{pRBp}$ ) expression.

When the $\mathrm{pRB}$ factor was 0 , cyclin $\mathrm{D}$ was ineffective, and because $\mathrm{pRB}$ was ineffective, cyclin $\mathrm{E}$ lost the phosphorylation of pRBp, simply phosphorylation of p27, and because of its modification of $\mathrm{p} 27$, it had little effect on $\mathrm{p} 27$. So we ignore cyclin E, p27.

The postactivating factors Cdhli and Cdhla were used in the internal regulation of cells, and their synthesis and regulation processes were neglected under the established values.

According to Figure 3, we conclude the final simplified equation: 


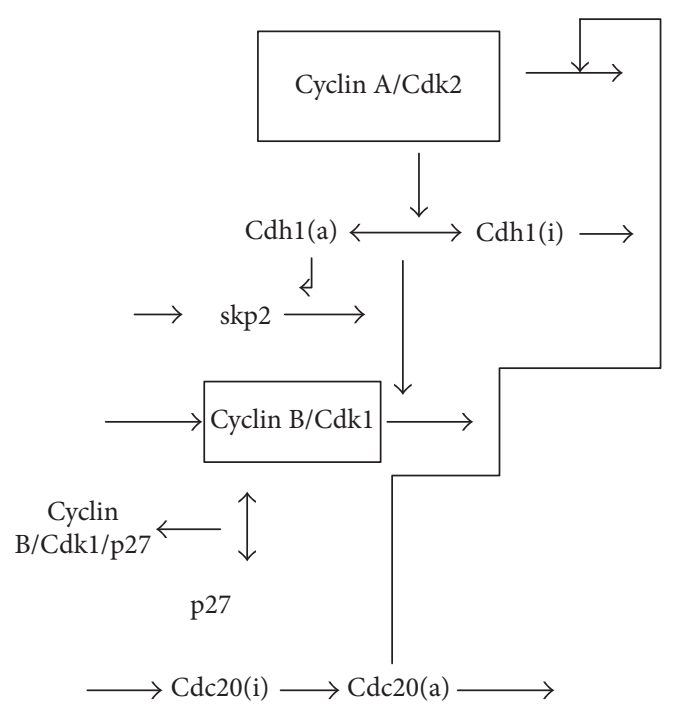

FIgURE 3: Simplified cell model.

$$
\begin{aligned}
\frac{d A}{d t}= & V_{\mathrm{e} 2 \mathrm{fa}}-V_{\mathrm{da}} * \mathrm{Cdc} 20 \mathrm{a} * \frac{A}{k_{\mathrm{da}}+A}-k_{\mathrm{dda}} \\
& * A \\
\frac{d \mathrm{Cdh} 1 \mathrm{a}}{d t}= & V_{1 \mathrm{cdh} 1} * \frac{1-\mathrm{Cdh} 1 \mathrm{a}}{k_{1 \mathrm{cdh} 1}+1-\mathrm{Cdh} 1 \mathrm{a}}-V_{2 \mathrm{cdh} 1} \\
& * A * \frac{\mathrm{Cdh} 1 \mathrm{a}}{k_{2 \mathrm{cdh} 1}+\mathrm{Cdh} 1 \mathrm{a}} \\
\frac{d B}{d t}= & V_{\mathrm{b}}-k_{\mathrm{db} 2} * \mathrm{Cdh} 1 \mathrm{a} * \frac{B}{k_{\mathrm{bm} 2}+B}-k_{\mathrm{db}} * B \\
\frac{d \mathrm{Cdc} 20 \mathrm{a}}{d t}= & V_{\mathrm{m} 1 \mathrm{~b}} * B * \frac{1-\mathrm{Cdc} 20 \mathrm{a}}{k_{1 \mathrm{~b}}+1-\mathrm{Cdc} 20 \mathrm{a}}-V_{\mathrm{m} 2 \mathrm{~b}} \\
& * \frac{\mathrm{Cdc} 20 \mathrm{a}}{k_{2 \mathrm{~b}}+\mathrm{Cdc} 20 \mathrm{a}} .
\end{aligned}
$$

( $V_{\mathrm{e} 2 \mathrm{fa}}$ is the internal synthesis rate of protein $\mathrm{A}, V_{\mathrm{da}}$ is the degradation rate, and $k_{\mathrm{dda}}$ is the modifier coefficient. $V_{1 \mathrm{cdh}}$ is the internal synthesis rate of protein Cdhla; $V_{2 \mathrm{cdh} 1}$ is the degradation rate of protein Cdhla. $V_{\mathrm{b}}$ is the internal synthesis rate of protein $\mathrm{B} ; k_{\mathrm{db} 2}$ and $k_{\mathrm{db}}$ are the modifier coefficients. $V_{\mathrm{mlb}}$ is the internal synthesis rate of protein Cdc20a; $V_{2}$ is its degradation rate of protein Cdc20a; $k_{1 \mathrm{~b}}$ and $k_{2 \mathrm{~b}}$ are protein Cdc20a's modifier coefficients.)

\section{Experimental System Simulation}

The experimental environment for this experiment is Matlab2012a version, 64-bit Win7 system, CPUi5-4790T, core frequency $2.0 \mathrm{GHZ}$, and memory $6 \mathrm{G}$.

In the experiment of simplified model, all of our intrinsic parameters were derived from the whole model of the cell, and the parameters were adjusted to the basis of the existing experimental proof, which was beneficial to the experiment.

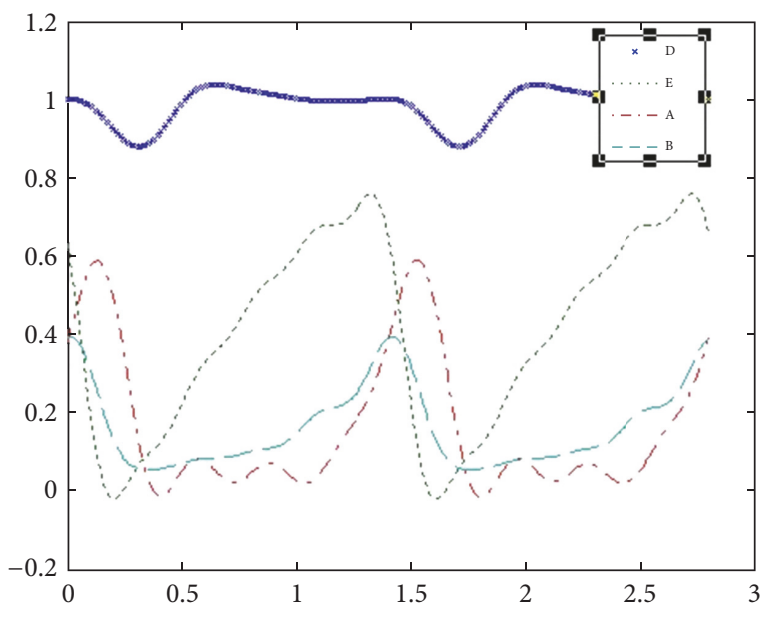

FIgURE 4: Complete cell division system simulation.

Table 2 shows the internal parameters of simplified equation (12) for the model.

The internal parameter was brought into the equation of the simplified model, and the function ode45s (RungeKutta method) was used to solve the high order differential equation of the complete model of the cell, and the simulation results were obtained.

Figure 4 shows the results of our overall model of cell division, which expressed four periodic proteins that were involved in the process of cell division. They were cyclin D, cyclin E, cyclin A, and cyclin B (the rectangle diagram in the upper right corner of Figure 4; the star line was cyclin D, short dashed line was cyclin E, the point line was cyclin A, and the long dashed line was cyclin B).

Through experimental simulations, we set the values of the variables of the various proteins in the cell and set their initial values at the same time. Our model entered the simulation with the passage of time. In the simulation results of the model, we could observe the various periodic rules of the four periodic proteins in the cells at the beginning of cell division and how their relationship changed.

The simulation results of this model completely showed the process and periodicity of the four major proteins in the cell division cycle. Cyclin D entered the G1 phase after the cells began to divide; then cyclin $\mathrm{D}$ began to increase gradually. After that the cells were introduced into the $S$ phase, the expression of protein $\mathrm{E}$ began to rise gradually. With the increase of cyclin E, the cells began to flow through $S$ phase and enter the G2 phase. Cycle protein D began to decrease gradually. During the S/G2 period, circulating proteins $A$ and $B$ began to increase. When the cells entered the $S$ phase, protein E began to decline rapidly, because $\mathrm{G} 2$ to $\mathrm{M}$ period is very short, so the intracellular circulating protein $\mathrm{D}$, protein $\mathrm{E}$, and protein A rapidly decline. When the cells passed $\mathrm{M}$ phase and completed the division, the intracellular protein content of each cycle decreased to a minimum. After entering a number of cycles, we reach the end of the split points.

In the second step, as the overall model of the cell division system was too complex, we must simplify it in the future when applied to actual industrial equipment. According to 
TABLE 2: Simplified parameter table.

\begin{tabular}{lc}
\hline Parameter & Simulation value \\
\hline$v e 2 \mathrm{fa}$ & $0.1 \mu \mathrm{M}^{-1}$ \\
$\nu \mathrm{da}$ & $0.3 \mathrm{~h}^{-1}$ \\
$k \mathrm{da}$ & $0.1 \mu \mathrm{M}$ \\
$k \mathrm{dda}$ & $0.1 \mathrm{~h}^{-1}$ \\
$v \mathrm{cdh} 1$ & $1 \mu \mathrm{M}^{-1}$ \\
$v 2 \mathrm{cdh} 1$ & $4 \mathrm{~h}^{-1}$ \\
$k \mathrm{cdh} 1$ & $0.01 \mu \mathrm{M}$ \\
$k 2 \mathrm{cdh} 1$ & $0.01 \mu \mathrm{M}$ \\
$v \mathrm{~b}$ & $0.1 \mu \mathrm{M} \cdot \mathrm{h}^{-1}$ \\
$k \mathrm{db} 2$ & $2 \mathrm{~h}^{-1}$ \\
$K \mathrm{bm} 2$ & $0.1 \mu \mathrm{M}$ \\
$k \mathrm{db}$ & $0.5 \mathrm{~h}^{-1}$ \\
$v \mathrm{~m} 1 \mathrm{~b}$ & $2 \mathrm{~h}^{-1}$ \\
$v \mathrm{~m} 2 \mathrm{~b}$ & $0.7 \mu \mathrm{M} \cdot \mathrm{h}^{-1}$ \\
$k \mathrm{lb}$ & $0.1 \mu \mathrm{M}$ \\
$k 2 \mathrm{~b}$ & $0.1 \mu \mathrm{M}$ \\
\hline
\end{tabular}

Table 2, we simulated the simplified cell model and obtained the results after ignoring some of the values that did not affect the overall rule.

In the simplified model of the model, the four main features we extracted were still inherently periodic and maintain a periodic curve similar to the global model. We could observe the cycle variation of the cyclin in the four main dominant simplified models and the change of the period after the change factor in the simulation of the simplified model. In this paper, Figure 5 shows the periodicity of the cyclin A, cyclin B, Cdc20a, and Cdhla in the simplified model (where the blue dot was cyclin A, the red solid line was B, the cyan dotted line was Cdhla, and the indigo dotted line was Cdc20a). Split starts from 0 seconds. When the telomere is in accordance with the rule of linear decline to a certain value, the split stopped. Starting from 0 seconds, protein A began to increase first, and cyclin A synergistic Cdhla began to gradually increase. At about 1-second position, Cdchla began to drop. Since cyclin A promotes cyclin B expression, cyclin A continues to rise, and protein $B$ began expressing at the end of the first period, and the synergistic factor Cdc20a of cyclin $\mathrm{B}$ also began to rise. To the end of the division, they were attributed to the minimum. Because it was a simplified model, the cell division cycle was not complete but still can express the division of cells.

Figure 6 shows the simulation results of intracellular splitting after modifying the internal parameters of the model. When the internal influencing factor was modified, the expression cycle of each protein in the cell was abnormal; the expression cycle became longer but did not affect the normal division of the cell. However, when the impact factor dropped to a certain extent, it would influence the experimental results in Figure 7: the expression of the cell cycle protein was no longer cyclical (cell cycle damage: the cells are not split); we could analyze the cells effects of internal factors in cell division cycle.

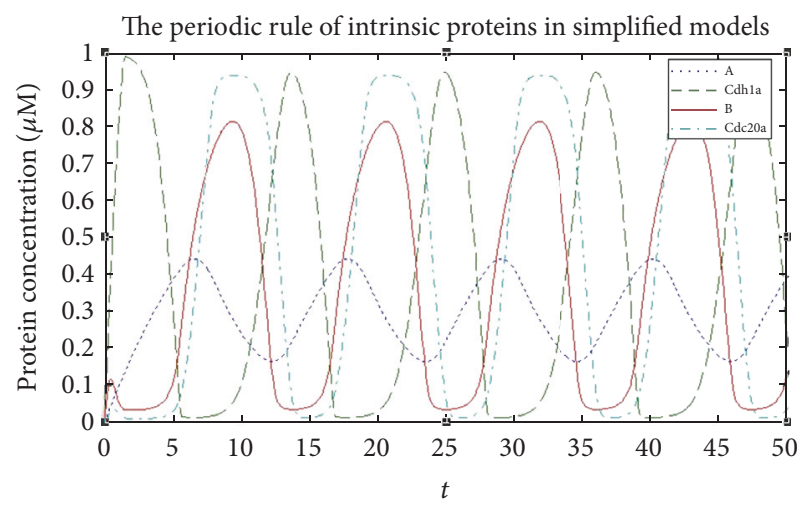

Figure 5: Periodicity of cyclin in the simplified system.

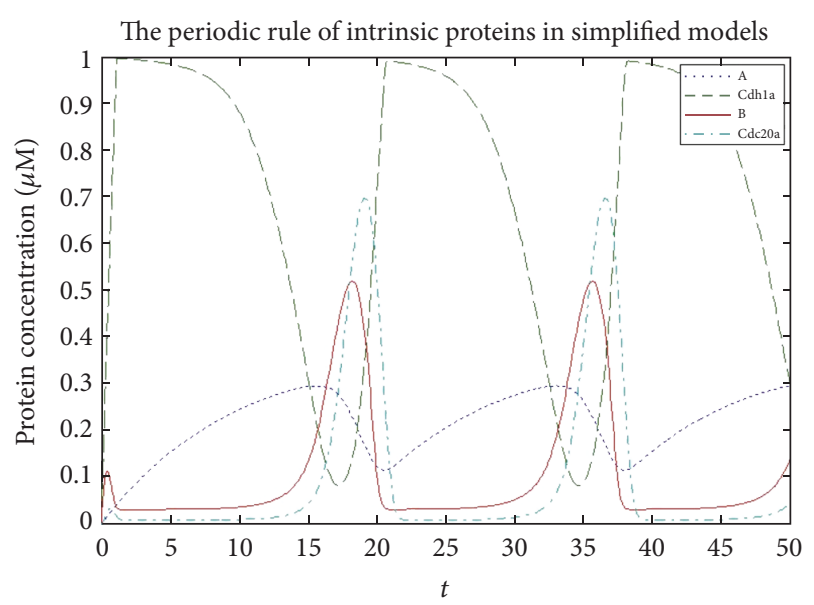

FIGURE 6: Periodicity of cyclin in the simplified system (changed internal parameters).

By comparing the three graphs, it was possible to draw a simple conclusion that the cell division was controlled by its internal division factor and at the expression concentration of its periodic protein. When we modify the parameters of the cell division in the model, the cell division will change (which is shown in the case where the division period is longer and the division time was different). Similarly, through realtime monitoring of internal parameters, drawing waveforms, we could clearly and intuitively observe the process of intracellular division and cell health and life conditions. From the experiment, we could have a complete understanding of the cell cycle and life cycle, so as to predict the cell life.

In modern industrial equipment, the life cycle of industrial equipment is determined by a number of similar intrinsic factors and also in the performance characteristics of some of its components. We need to understand the cell life by studying cell division and then discover the relationship between its intrinsic and performance characteristics in industrial equipment (in a particular direction in the future). It is our next task to link this conclusion to the life expectancy of large industrial equipment in our reality. Through the abstraction of cell division and lifespan prediction model, we abstract 


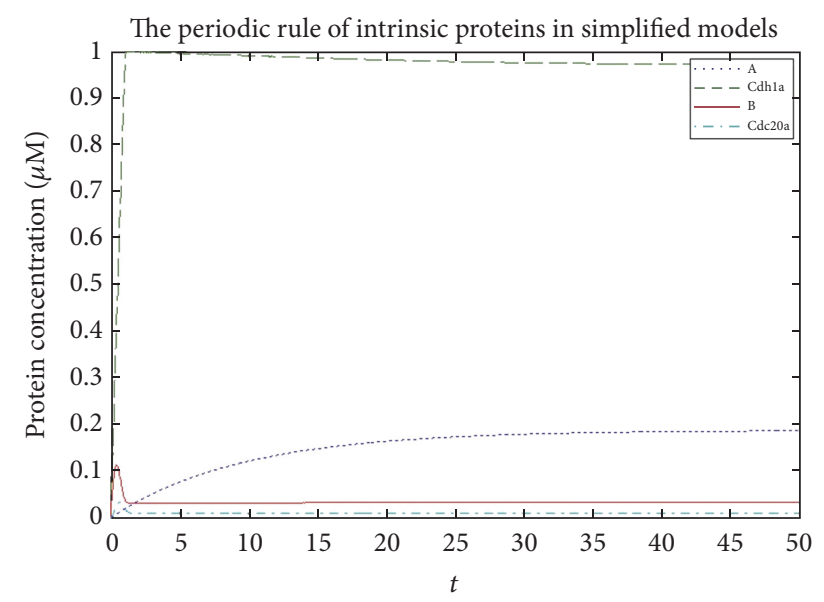

Figure 7: Termination of cell division.

a lifetime prediction model for industrial equipment and conduct bionic research on the life of industrial equipment.

\section{Conclusion}

Because cell division mechanism has many applications in engineering [9], the aim of this paper is to apply the model of the life cycle prediction of industrial equipment by studying the regularity of the cell life in the natural biological evolution.

Based on the experimental study and analysis, a cell division model was established to study the cell division cycle and mitotic factors. At the same time, through the observation and analysis of a variety of cell division processes, we use simplified parameters and other means to simplify the cell division model.

Finally, we used a simplified model for simulation experiments. After analyzing the results, it showed the following.

By controlling the concentration of some key factors in cell division, the effect on the normal life of a cell can be expressed intuitively. The reduction in the synthesis of cyclin A inhibits cell division and reduces the expression of cyclin B, thereby preventing cell division. But when the cyclin reaches a certain concentration the cells will continue to divide and the cell division cycle grows. Similarly, in normal industrial equipment, we can still find the parameters of the device that correspond to the factors affecting the cell division according to the model of cell division. Then, by modeling the complex system, we can predict the lifetime of the equipment.

\section{Conflicts of Interest}

The authors state that there are no conflicts of interest regarding the publication of this paper.

\section{References}

[1] C. Hu, Z. Zhou, J. Zhang, and X. Si, "A survey on life prediction of equipment," Chinese Journal of Aeronautics, vol. 28, no. 1, pp. 25-33, 2015.
[2] F. Ahmadzadeh and J. Lundberg, "Remaining useful life prediction of grinding mill liners using an artificial neural network," Minerals Engineering, vol. 53, pp. 1-8, 2013.

[3] D. McKenney and J. A. Nickel, "Mathematical model for cell division," Mathematical and Computer Modelling, vol. 25, no. 2, pp. 49-52, 1997.

[4] T. Hu, H. Xun, X. Zhilong et al., "Systematic modeling and analysis of cell cycle regulation mechanism of fission yeast," Science Bulletin, vol. 50, no. 15, pp. 1605-1612, 2005.

[5] A. d'Onofrio, "Mathematical analysis of the Tyson model of the regulation of the cell division cycle," Nonlinear Analysis: Theory, Methods \& Applications, vol. 62, no. 5, pp. 817-831, 2005.

[6] Y. Zhaoying and L. Jinliang, "A brief history of the development of cell cycle and its cycle control research", Journal of Chinese Medical History, vol. 34, no. 3, pp. 176-179, 2004.

[7] N. Wiriyasermkul, V. Boonjing, and P. Chanvarasuth, "A meiosis genetic algorithm," in Proceedings of the 7th International Conference on Information Technology: New Generations (ITNG '10), pp. 285-289, Las Vegas, Nev, USA, April 2010.

[8] C. E. Dow, A. Rodger, D. I. Roper, and H. A. van den Berg, "A model of membrane contraction predicting initiation and completion of bacterial cell division," Integrative Biology, vol. 5, no. 5, pp. 778-795, 2013.

[9] Vaishnavikannan and S. Jhajharia, "Using cell division for text to image encryption," in Proceedings of the 10th International Conference on Intelligent Systems and Control (ISCO '16), Coimbatore, India, January 2016. 


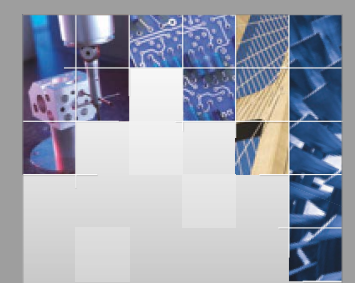

\section{Enfincering}
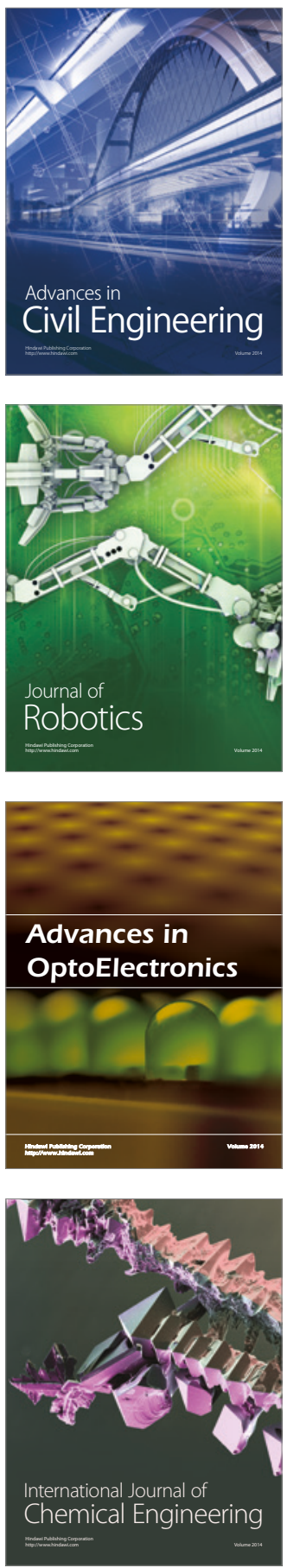

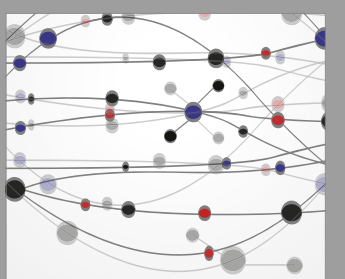

The Scientific World Journal

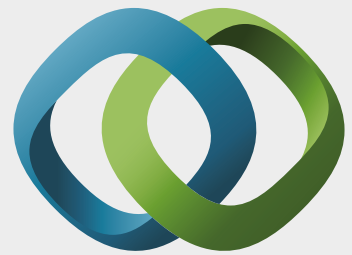

\section{Hindawi}

Submit your manuscripts at

https://www.hindawi.com
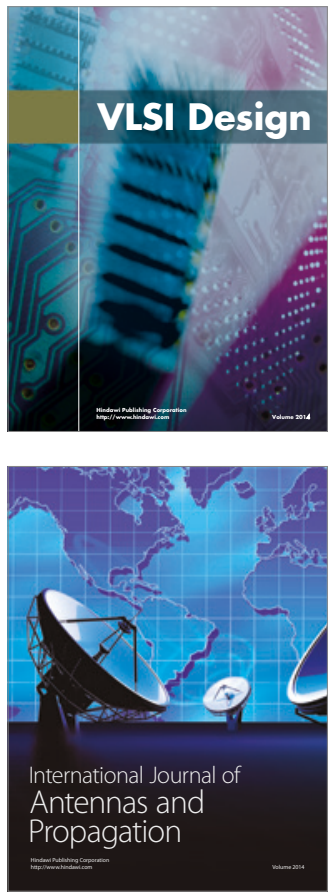

\section{Rotating}

Machinery
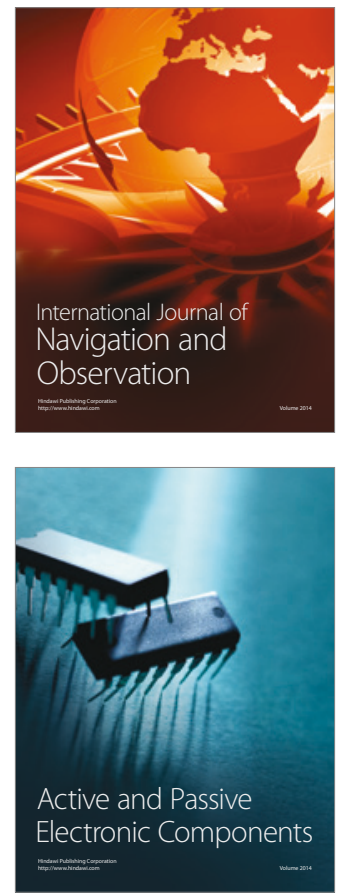
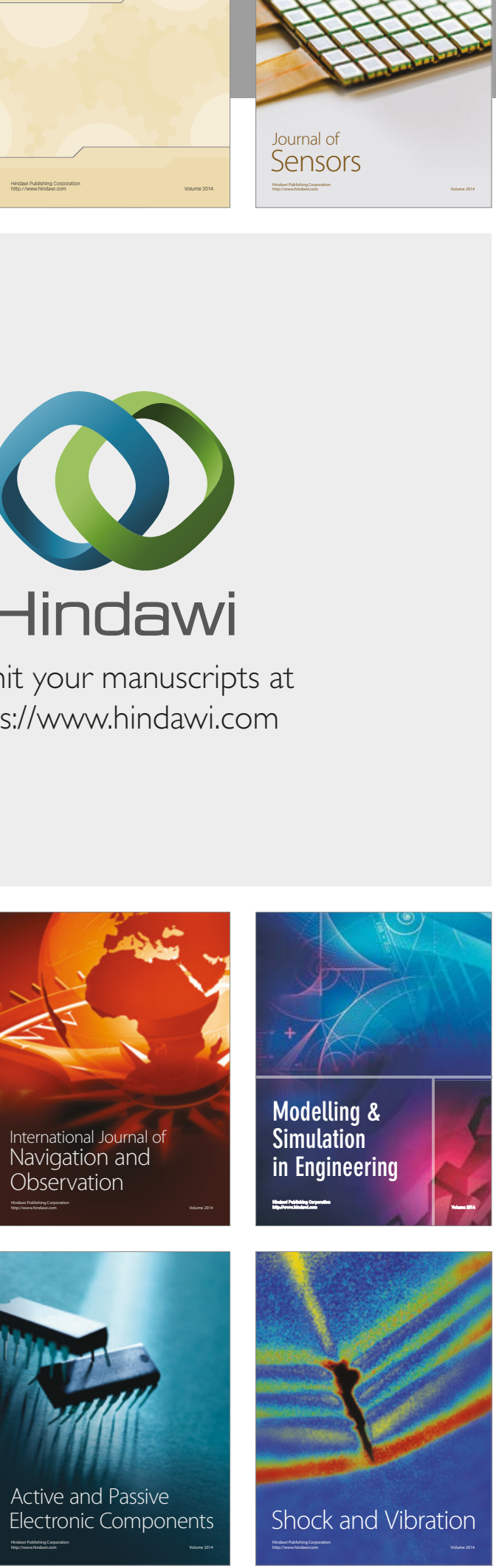
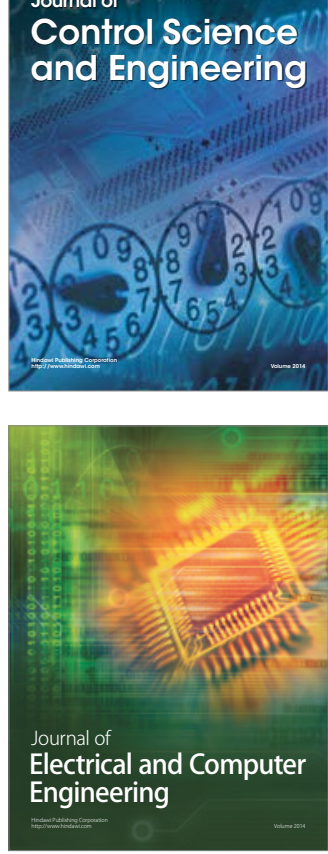

Distributed

Journal of

Control Science

and Engineering
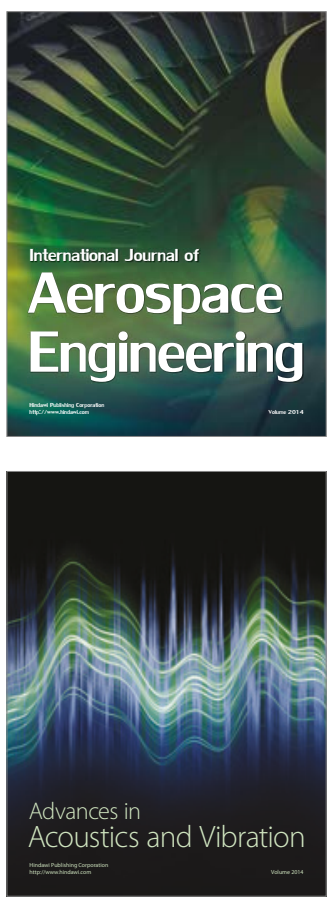

Sensor Networks 